\title{
Endovascular treatment and morphology typing of chronic ostial occlusion of the subclavian artery
}

\author{
JING-LIANG ZHANG ${ }^{1,2^{*}}$, WEI TONG ${ }^{3 *}$, JIAN-FENG LV $^{2}$ and LU-XIANG CHI ${ }^{2}$ \\ ${ }^{1}$ Department of Aerospace Medicine, The Fourth Military Medical University, Xi'an, Shaanxi 710032; \\ ${ }^{2}$ Department of Cardiology, Southwest Hospital, The Third Military Medical University, Chongqing 400038; \\ ${ }^{3}$ Department of Cardiology, Chinese PLA General Hospital, Beijing 100853, P.R. China
}

Received December 11, 2015; Accepted January 13, 2017

DOI: $10.3892 / \mathrm{etm} .2017 .4203$

\begin{abstract}
Chronic obstructive lesions of the subclavian artery (SCA) often result in subclavian steal syndrome, which leads to arm claudication, transient cerebral ischemia, and other serious complications. The lesions are classified as stenosis and occlusion, according to the degree of obstruction. Unlike totally occlusive lesions, including ostial occlusions, stenotic lesions have an excellent technical success rate. In the present study, ostial occlusions were classified into 4 types according to their angiographic appearance. A total of 8 patients $(6$ male, 2 female) with SCA occlusions were treated with percutaneous transluminal angioplasty and stenting over a 4-year period. Mean patient age was 65.6 years (range, 60-72 years). In total, 9 self-expanding and 1 balloon-expandable stent were implanted at the ostia of the SCA in 7 of the patients. One female patient did not undergo stenting. Bleeding at the access site was noted in 2 patients and was controlled by gauze pressure. The patient that did not undergo stenting was lost to follow-up with symptoms of a transient ischemic attack at 3 months. The mean follow-up time for the remaining 7 patients was 15.7 months (range, 1-36 months). No ischemic symptoms, neointimal hyperplasia, or restenosis was observed in these patients. The transfemoral artery operation approach is preferred for rat-tail and peak type occlusions, whereas the dual approach involving both femoral and radial arteries is preferred for hilly and plain type occlusions. The angiographic morphology typing used in the present study may serve as a reference to decide upon the interventional operation strategy to be used for improving the technical success rate.
\end{abstract}

Correspondence to: Dr Lu-Xiang Chi, Department of Cardiology, Southwest Hospital, The Third Military Medical University, 30 Gaotanyan Street, Chongqing 400038, P.R. China

E-mail: chi68754271@126.com

*Contributed equally

Key words: angiography, percutaneous transluminal angioplasty, stent, subclavian artery occlusion, subclavian artery ostium

\section{Introduction}

Chronic obstructive lesions of the proximal subclavian artery (SCA) lead to retrograde blood flow in the ipsilateral vertebral artery, which results in symptoms such as vertebrobasilar insufficiency, upper limb claudication, and transient ischemic attacks (1). The most common cause of such obstructive lesions is atherosclerosis (2).

The present treatment methods for chronic obstructive lesions of the SCA include extra-anatomic carotid-subclavian bypass, percutaneous endovascular angioplasty and stenting (1). Although open surgery has a better patency compared with endovascular treatment (3), experienced physicians generally prefer endovascular treatment as the first-line treatment, reserving open surgical treatment for patients with total occlusive lesions or stenotic lesions that are anatomically unsuitable for endovascular repair (2).

SCA lesions are classified as stenosis or occlusion, according to the severity of obstruction (4). Chronic total occlusive lesions, particularly those located at the ostium of the SCA, are more complicated and difficult to operate on (5). Therefore, the technical success of surgery is excellent for stenosis, whereas for occlusions it varies largely (1). The primary reason for this is that in the ostium of the SCA the guiding catheter cannot be stably fixed, and the guide wire struggles to cross the proximal fibrous cap of the occlusive lesions (5).

Noguchi et al (6) demonstrated that the presence of calcification, the length of the occlusion and the presence of multi-vessel disease were independent predictors of the procedural success rate for percutaneous transluminal coronary angioplasty of chronic total occlusions.

The aim of the present study was to classify ostial occlusions of the SCA according to their angiographic morphology in order to determine the role of angiographic morphology in SCA occlusions and investigate the interventional operation strategy and success rate.

\section{Patients and methods}

Patients. The inclusion criteria for the present study were as follows: Total occlusion of the SCA, occlusions located in the proximal segment (from the ostium of the SCA to the vertebral artery) (7), and attempted percutaneous transluminal 
angioplasty or stenting for the occlusions. The exclusion criteria were: SCA hemodynamically irrelevant stenosis, $>2$ SCA occlusions or occlusions developed with collateral circulation.

Eventually, the present study included seven patients with total occlusion of the left SCA (LSCA) and one patient with total occlusion of the right SCA (RSCA), who were treated at the Southwest Hospital or Xinqiao Hospital (Chongqing, China) between August 2010 and April 2014. A total of 6 male and 1 female patients with a mean age of 65.6 (range, 60-72) years were successfully treated with percutaneous transluminal angioplasty and stenting. One 71-year-old female patient with RSCA occlusion did not respond to endovascular treatment and therefore underwent medical therapy instead of stenting. Patient demographics and clinical characteristics, including the presence of co-morbidities, are summarized in Table I. Total occlusion of the SCA was diagnosed in all patients via duplex ultrasound evaluation, computed tomography angiography (CTA) or conventional angiography. The lesions present in 7 patients were caused by atherosclerosis resulting from their history of hypertension in conjunction with dyslipidemia or diabetes. The RSCA occlusive lesion in the female patient treated with stenting was attributed to her history of Takayasu arteritis and hydrocortisone therapy. The present study was approved by the review committee of Third Military Medical University (Chongqing, China) and written informed consent was obtained from all patients prior to participation in the current study. All patients and their families were informed about the intended use of self-expanding or balloon-expandable stents in the SCA and the investigative nature of this procedure.

Percutaneous transluminal angioplasty. All patients were premedicated with aspirin (100 mg/day; Bayer AG, Leverkusen, Germany) and clopidogrel (75 mg/day; Sanofi S.A., Paris, France) ommencing 3 days prior to the operation. All procedures were performed under local anesthesia of $100 \mathrm{mg}$ Lidocaine (China Otsuka Pharmaceutical Co. Ltd., Tianjin, China). Right femoral access was obtained via a standard Seldinger puncture (8), followed by the placement of an $8 \mathrm{Fr}$ introducer sheath. Anticoagulation was preliminarily achieved with an initial bolus of 6,000 IU intravenous heparin (Shanghai No. 1 Biochemical \& Pharmaceutical Co. Ltd., Shanghai, China). An 8 Fr guiding catheter was then advanced over the wire into the ostium of the LSCA, and an angiogram was obtained in the anteroposterior and left anterior oblique (45 degree) views to confirm the location, length and degree of the lesion. According to the angiographic morphology, the occlusions of the 8 patients were classified as: Rat-tail, peak, hilly or plain types (Fig. 1). All angiographic morphologies, the treatment techniques used and follow-ups are summarized in Table II.

Rat-tail type occlusion. The angiography of Patient 1 revealed subtotal occlusion of the LSCA with a very narrow eccentric lumen, the outline of which resembled a rat's tail (Fig. 1A). Using digital road mapping, a 0.014-inch Pilot 150 guiding wire (Abbott Vascular; Abbott, Abbott Park, IL, USA) was used to gently penetrate the lesion across the lumen, and a 4x20 mm Sprinter Legend balloon catheter (Medtronic, Minneapolis, MN, USA) was inflated to dilate the lesion over the wire. An 8x30 mm Precise Self-Expanding Stent (Cordis Corporation, Hialeah, FL, USA) and a 9x20 mm Protégé Self-Expanding
Stent (Medtronic) were procedurally navigated over the exchange wire and mutually overlapped across the occlusive segment of the LSCA. Extreme care was taken to ensure that the stent covered the entire atherosclerotic lesion.

Peak type occlusion. The angiographies of 4 patients revealed totally occlusive SCA with Thrombosis in Myocardial Infarction (TIMI) grade 0 antegrade flow. This type of lesion was classified as peak type occlusion (Fig. 1B). The occlusion was crossed by a 0.014 -inch guiding wire, with the wire tip repeatedly stabbing the top of the 'peak'. The lesion was subsequently dilated using a Sprinter Legend or percutaneous transluminal angioplasty (PTA) balloon catheter (Invatec S.p.A., Roncadelle, Italy) and an appropriate stent was applied to the lesion. In Patient 5, 1.5x20 mm and 2x20 mm Sprinter Legend balloon catheters were introduced to dilate the occlusion once the guiding wire had crossed the RSCA occlusion via the femoral access; however, the angiography revealed $\sim 40 \%$ residual stenosis. A $5 \times 30 \mathrm{~mm}$ EV3 balloon catheter was therefore inflated to dilate the stenosis, and a subsequent angiography demonstrated satisfactory recanalization of the RSCA with $<10 \%$ residual stenosis. An $8 \times 30$ mm Protégé Self-Expanding Stent was subsequently deployed at the ostium of the LSCA.

Hilly type occlusion. The angiographies of Patient 6 and Patient 7 revealed totally occlusive ostia of the LSCAs, with TIMI grade 0 antegrade flow. As an occlusion of this type resembles a hill, it is referred to as a 'hilly' type occlusion (Fig. 1C). A combined femoral and radial approach was used in patients with this type of occlusion. Both the 0.018-inch guiding wire and the 0.035 -inch guiding wire failed to cross the lesions via femoral access in Patient 6. A 0.014-inch Pilot 150 wire eventually succeeded in crossing the occlusion following repeated gentle attempts from the left radial side. Subsequently, a PTA balloon catheter was used to dilate the lesion, and 12x40 mm and 10x20 mm Protégé Self-Expanding stents were procedurally advanced coaxially over the wire and deployed across the occlusion. A 0.014-inch stiff ChoICE PT Extra Support wire (Boston Scientific, Marlborough, MA, USA) was inserted into the LSCA ostium via the femoral access in Patient 7. Repeated attempts to pass the wire through the occlusion with the support of a Sprinter Legend balloon catheter were unsuccessful. Another 0.014-inch Pilot 150 guiding wire was then selected. An angiography following approximately $2-\mathrm{cm}$ advancement of the Pilot 150 guiding wire revealed that the distal artery exhibited an antegrade flow; however, the wire tip was not in the lumen with the arterial dissection forming at the lesion. The patient and her family were informed about the situation and the procedure was immediately aborted.

Plain type occlusion. The angiography of Patient 8 revealed an occlusive lesion with TIMI grade 0 antegrade flow in the ostium of the LSCA. Occlusions of this type, with a flat bottom, are termed as 'Plain' type occlusions (Fig. 1D). A similar combined femoral and radial approach is used in patients with this type of occlusion. Both the 0.018-inch guiding wire and the 0.035 -inch guiding wire failed to cross the lesions even via the femoral access. A 0.014-inch Pilot 150 wire successfully crossed the occlusion from the left radial side. Subsequently, a PTA balloon 
Table I. Demographics and clinical characteristics of patients.

\begin{tabular}{lll}
\hline Patient no./age (y)/Sex & \multicolumn{1}{c}{ Symptoms } & \multicolumn{1}{c}{ Comorbidities } \\
\hline 1/60/M & Asymptomatic & CI \\
2/70/M & Upper limb claudication & CI, HTN, DM, CHD \\
3/62/M & Asymptomatic & CHD, HL \\
4/68/M & Upper limb claudication & HTN, DM, HL \\
5/62/F & Dizziness, upper limb claudication & TIA \\
6/65/M & Dizziness, upper limb claudication & CI, DM \\
$7 / 71 / \mathrm{F}$ & Drop attack, dizziness & HTN, DM, CHD \\
8/72/M & Vertigo, upper limb claudication & HTN, DM, HL
\end{tabular}

CHD, coronary heart disease; DM, diabetes mellitus; HL, hyperlipidemia; HTN, hypertension; CI, cerebral infarct; TIA, transient ischemic attack; M, male; F, female.

catheter was used to dilate the lesion and 9x30 $\mathrm{mm}$ and $8 \times 30 \mathrm{~mm}$ Precise Self-Expanding stents were procedurally advanced coaxially over the wire and deployed across the occlusion.

A final angiography was performed to evaluate the results of stent surgery and patency of the SCA as well as its normal antegrade flow.

Follow-up. All 8 patients were transferred to the cardiovascular intensive care unit following the procedure and subjected to electrocardiograph monitoring for $24 \mathrm{~h}$ prior to being moved to an ordinary ward. Patients were discharged 3 days later with a prescription of $100 \mathrm{mg} /$ day aspirin for life and $75 \mathrm{mg} /$ day clopidogrel for 3 months, unless otherwise indicated. All patients were evaluated by experienced physicians post-surgery and then periodically during the follow-up period. Follow-up Doppler ultrasound, CTA or angiography was performed every 3 months for the first 6 months, and every 6 months thereafter.

\section{Results}

Stenting and typing. A total of 9 self-expanding and 1 balloon-expandable stent were implanted in the SCA of 7 patients with totally occlusive lesions. In 3 patients, 2 stents were used, whereas a single stent was used in a further four patients. Final angiograms obtained at the end of the procedure confirmed satisfactory recanalization of the SCA with $<10 \%$ residual stenosis and good patency of stents in all cases. The endovascular procedure for arterial dissection via femoral access failed in one female patient. The lesions of the eight patients were categorized as follows according to their angiographic appearance: Rat-tail, 1/8 (12.5\%); peak, 4/8 (50\%); hilly type, 2/8 (25\%); and plain, 1/8 (12.5\%; Table II).

Complications. No major strokes or mortalities occurred within 30 days of the procedure. However, minor bleeding at the femoral access site was noted in 2 patients, which was controlled by applying gauze pressure. A post-procedure CTA of the female patient with arterial dissection revealed a tear between the intima and the media layer at the ostium of the LSCA. The patient was kept under close and continuous clinical observation. During the first 3 months, the patient still presented symptoms of transient ischemic attacks, such
A

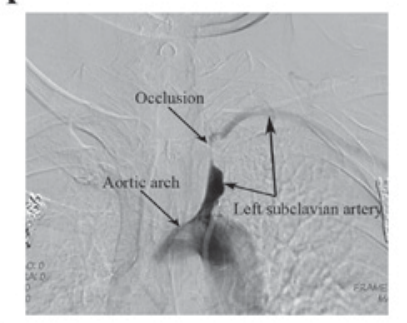

C

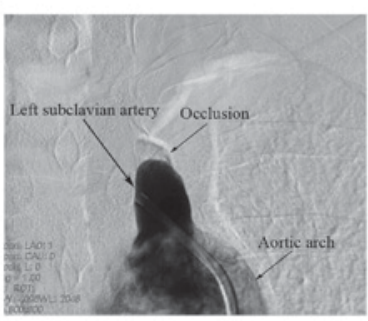

B

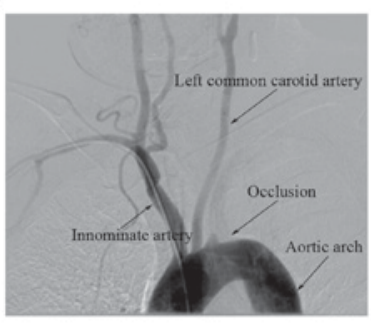

D

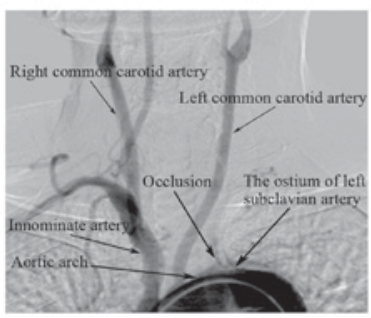

Figure 1. The occlusions of 8 patients were classified into 4 types according to the angiographic morphology. (A) Angiography of Patient 1 revealed subtotally occlusive LSCA with TIMI grade I antegrade flow, classified as a rat-tail type occlusion. (B) Angiography of Patient 3 revealed totally occlusive LSCA with TIMI grade 0 antegrade flow, classified as a peak type occlusion. (C) Angiography of Patient 6 revealed totally occlusive LSCA with TIMI grade 0 antegrade flow, classified as a hilly type occlusion. (D) Angiography of Patient 8 revealed totally occlusive LSCA with TIMI grade 0 antegrade flow, classified as a plain type occlusion. LSCA, left subclavian artery; TIMI, Thrombosis in Myocardial Infarction.

as vertebrobasilar insufficiency. However, she was lost to follow-up after 3-months as she gave no response to attempts at contact.

Follow-up. The 7 remaining patients attended a post-procedural follow-up following discharge from hospital. The mean follow-up time was 15.7 months (range, 1-36 months), whereas the total follow-up time varied among patients according to the date of their most recent Doppler ultrasound, CTA (Fig. 2), or angiography. No ischemic symptoms, including vertebrobasilar insufficiency, upper extremity ischemia, or transient ischemic attacks attributable to the procedure were observed during the follow-up period, and no evidence of neointimal 
Table II. Angiographic morphologies, treatment techniques, follow-up duration and results.

\begin{tabular}{|c|c|c|c|c|c|}
\hline $\begin{array}{l}\text { Patient } \\
\text { no. }\end{array}$ & $\begin{array}{l}\text { Location/Degree/ } \\
\text { Type of lesion }\end{array}$ & $\begin{array}{l}\text { Access of } \\
\text { approach }\end{array}$ & $\begin{array}{l}\text { Stent-craft } \\
\text { size }(\mathrm{mm})\end{array}$ & $\begin{array}{c}\text { Follow-up } \\
\text { duration }(\mathrm{m})\end{array}$ & Result \\
\hline 1 & LSCA Proximal/Subtotal occlusive/Rat-tail Type & Femoral (R) & $\begin{array}{c}8 \times 30,9 \times 20 \\
(\mathrm{SES})\end{array}$ & 19 & Patent; Recovered \\
\hline 2 & LSCA Proximal/Total occlusive/Peak Type & Femoral (R) & $9 \times 30(\mathrm{BAS})$ & 6 & Patent; Recovered \\
\hline 3 & LSCA Proximal/Total occlusive/Peak Type & Femoral (R) & $8 \times 30(\mathrm{SES})$ & 1 & Patent; Recovered \\
\hline 4 & LSCA Proximal/Total occlusive/Peak Type & Femoral (R) & $9 \times 30(\mathrm{SES})$ & 36 & Patent; Recovered \\
\hline 5 & RSCA Proximal/Total occlusive/Peak Type & $\begin{array}{l}\text { Femoral }(\mathrm{R}) \\
\text { and radial }(\mathrm{R})\end{array}$ & $8 \times 30(\mathrm{SES})$ & 6 & Patent; Recovered \\
\hline 6 & LSCA Proximal/Total occlusive/Hilly Type & $\begin{array}{l}\text { Femoral }(\mathrm{R}) \\
\text { and radial }(\mathrm{L})\end{array}$ & $\begin{array}{c}12 \times 40,10 \times 20 \\
(\text { SES })\end{array}$ & 17 & Patent; Recovered \\
\hline 7 & LSCA Proximal/Total occlusive/Hilly Type & Femoral (R) & & 3 & Non-patent; TIA \\
\hline 8 & LSCA Proximal/Total occlusive/Plain Type & $\begin{array}{l}\text { Femoral }(\mathrm{R}) \\
\text { and radial }(\mathrm{L})\end{array}$ & $\begin{array}{l}9 \times 30,8 \times 30 \\
\quad(\mathrm{SES})\end{array}$ & 25 & Patent; Recovered \\
\hline
\end{tabular}

LSCA, left subclavian artery; RSCA, right subclavian artery; L, left; R, right; SES, self-expanding stent; BAS, balloon-expandable stent; TIA, transient ischemic attack.
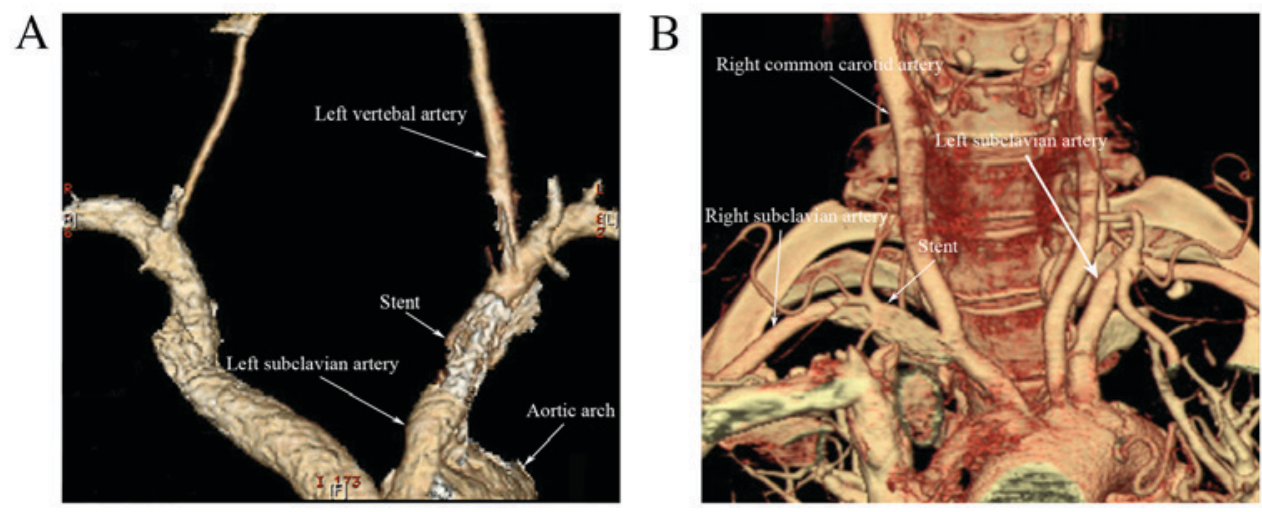

Figure 2. Rechecked computed tomography angiography at 6 months post-surgery reveals patency of subclavian artery and normal distal blood flow in (A) Patient 2 (Peak type occlusion) and (B) Patient 5 (Hilly type occlusion).

hyperplasia or restenosis was observed on follow-up angiography or color duplex Doppler.

\section{Discussion}

The present treatment methods for chronic obstructive lesions of the SCA consist of endovascular or surgical techniques (2). In 1980, Bachman and Kim (9), and Mathias et al (10) separately reported percutaneous transluminal angioplasty as a method for the treatment of SCA stenosis for the first time. Thereafter, multiple studies have confirmed the safety and effectiveness of endovascular treatment for this purpose (7,11-23). The prevalence of endovascular treatment for SCA lesions and the advancement of interventional techniques during the last 3 decades has led to $91-100 \%$ technical success of treatment for SCA lesions (1). Endovascular repair has been regarded as the primary choice for the treatment of SCA lesions as it is less invasive, has lower intraoperative and postoperative complication rates, better patient comfort and decreased hospital stay, particularly among patients at high risk of surgical complications $(1,2,24)$.
SCA lesions are classified as stenosis or occlusion according to the severity of obstruction (4). Multiple studies have demonstrated that the endovascular technical success for stenosis is excellent, whereas the occlusions are more challenging to treat. The endovascular treatment success rate with interventional techniques for stenotic lesions is $94-100 \%(7,12,18,23,25-33)$, whereas for totally occlusive lesions it is $47-100 \%(7,12,18,19,23,25-34)$ (Table III). It may therefore be concluded that the endovascular treatment technique for stenotic lesions is well established, whereas that for occlusive lesion is more difficult and controversial, particularly when the occlusion is located at the ostium of the SCA.

Chronically occlusive lesions in the SCA may be caused by atherosclerosis, Takayasu arteritis, giant cell arteritis, FMD, and radiation-induced arteriopathy; of these, atherosclerosis is the primary cause (2). A previous study (35) investigating the chronically occluded coronary artery reported that the typical chronic occlusion may be classified as 'soft', 'hard', or a mixture of both. Soft plaque consists of cholesterol-laden cells and foam cells with loose fibrous tissue and neovascular 
Table III. Summary of the published series of PTA or stenting-PTA of total occlusions of the subclavian artery $(7,12,18,19,23,25-34)$.

\begin{tabular}{|c|c|c|c|c|c|c|}
\hline Author & $\begin{array}{c}\text { Technical success } \\
\text { of stenotic lesion }(\%)\end{array}$ & $\begin{array}{l}\text { Technical success of } \\
\text { occlusive lesion }(\%)\end{array}$ & $\begin{array}{l}\text { Number } \\
\text { of patients }\end{array}$ & $\begin{array}{c}\text { Number } \\
\text { of operations }\end{array}$ & Year & (Refs.) \\
\hline Miyakoshi & 100 & 80 & 36 & 36 & 2012 & $(25)$ \\
\hline Aziz & 94 & 64 & 1300 & & 2011 & $(26)$ \\
\hline Sixt & 100 & 87 & 107 & 108 & 2009 & (27) \\
\hline Palchik & 100 & 54 & & 67 & 2008 & (7) \\
\hline AbuRahma & 100 & 92 & 121 & 121 & 2007 & (28) \\
\hline Przewlocki & 100 & 72 & 75 & 76 & 2006 & (29) \\
\hline Woo & 100 & 57 & 25 & 27 & 2006 & (23) \\
\hline De Vries & 100 & 65 & 110 & 109 & 2005 & (12) \\
\hline Brountzos & 98 & 85 & 47 & 49 & 2004 & (18) \\
\hline González & & 100 & 9 & 9 & 2002 & (19) \\
\hline Henry & 100 & 47 & 113 & 113 & 1999 & (30) \\
\hline Sueoka & 100 & 100 & 7 & & 1996 & (31) \\
\hline Criado & 100 & $<90$ & 26 & 30 & 1995 & (32) \\
\hline Kumar & 100 & 100 & 27 & 31 & 1995 & (23) \\
\hline Mathias & & 83 & 46 & & 1993 & (34) \\
\hline
\end{tabular}

PTA, percutaneous transluminal angioplasty.

channels. Older occlusions, defined as 'hard plaques', have higher concentrations of calcium and collagen components.

The typical atherosclerotic plaque of chronic occlusions is primarily characterized by a collagen-rich extracellular matrix, intra- and extracellular lipids, smooth muscle cells and mixed components, including a small quantity of cholesterol, dense collagen and calcium deposits (35). The collagen-rich fibrous tissue is particularly dense at proximal and distal ends of the lesion, referred to as proximal and distal fibrous caps, respectively (36). The distal fibrous cap of a chronic occlusion is considered to be less resistant compared with the proximal one $(37,38)$.

Fibrous caps of the occlusion lesions caused by atherosclerosis are typically solid following the long-term process of formation and calcification (35). Therefore, the present authors suggest that successful passage of the wire through the occlusive lesion is the key step of recanalization. In the retrograde approach, the catheter could be delivered over a shorter distance and remain in the distal SCA, gaining more stability and axial support and avoiding the more rigid proximal fibrous cap (5). When traversing the occlusion via the femoral artery is unsuccessful, the guiding wire may succeed using a retrograde approach via the radial access.

On the basis of the above analysis and the findings of the present study, chronic total occlusions at the ostia of the SCA were classified into 4 types according to the angiographic morphology of the proximal vessel (Fig. 1), which is important for selecting the optimal interventional operation strategy.

Rat-tail type lesions are not completely occlusive, exhibiting TIMI grade I antegrade flow in the angiographic appearance (Fig. 1A). This suggests that such lesions are formed over a short period of time, as they consist of cholesterol-laden cells and foam cells with loose fibrous tissue and neovascular channels (35). This suggests that the true lumen, to which the tip of the Rat-tail points, has not been totally occluded, and the proximal fibrous cap is thin and soft, allowing the guide wire to cross with relative ease (38).

Peak type lesions are completely occlusive and exhibit TIMI grade 0 antegrade flow in angiographic appearance (Fig. 1B). This type of occlusion forms later and mainly consists of loose fibrous tissue with slight calcification (35). The lumen tapers gradually from the distal end and becomes occlusive at the proximal end (38), suggesting that the tip of the peak points to the true lumen. When the guiding wire pierces the dissection, it is feasible to perform PTA and stenting as long as the guiding wire reaches the true lumen at the distal end prior to the vertebral artery ostium.

The transfemoral artery operation approach is preferred for rat-tail and peak type occlusive lesions as the guiding wire is able to easily traverse to the distal lumen following repeated gentle operative attempts.

Hilly type lesions are completely occlusive, exhibiting TIMI grade 0 antegrade flow in angiographic appearance. This type of occlusion takes a long time to form and consists of highly calcified tissue and a dense fibrous cap (35). The concave proximal fibrous cap does not have a specific point (Fig. 1C). The guiding wire did not stabilize on insertion via the femoral artery and the puncture point may not be determined; the wire always entered the dissection site instead of the true lumen, even with repeated insertion attempts.

Plain type lesions are completely occlusive, exhibiting TIMI grade 0 antegrade flow in angiographic appearance (Fig. 1D). They have a lengthy formation time, and consist of a dense fibrous cap with severe calcification (35). The guiding wire did not stabilize on insertion via the femoral artery, and the puncture point may not be determined.

In patients with hilly and plain type occlusions, both the 0.018-inch V-18 guiding wire and the 0.035-inch Amplatz 
Super Stiff guiding wire were unsuccessful in traversing the lesions via the femoral access. The occlusion was finally traversed successfully by a 0.014 -inch Pilot 150 wire via the radial artery.

The dual approach, which includes the femoral and radial artery, is preferred in hilly and plain type occlusive lesions. The catheter is inserted via the femoral artery to observe the location, length and degree of the lesion. The guiding wire is delivered via the radial artery to cross the occlusion and deploy the stent $(5,38)$. The hilly type occlusion, which is treatable using the dual approach, was observed in Patient 6. Attempts to traverse the occlusion via the femoral artery failed and ultimately led to dissection, therefore the operation was aborted. The retrograde approach via the radial artery should be attempted to traverse the occlusion and deploy the stent covering the dissection.

The present study had some limitations, due to the small number of patients and the fact that all of the occlusions included were caused by atherosclerosis.

In conclusion, the findings of the present study demonstrate that the transfemoral artery operation approach is preferred in rat-tail and peak type occlusions, whereas the dual approach, including both femoral and radial arteries, is preferred for the treatment of hilly and plain type occlusions. The angiographic morphology typing used in the present study serves as a reference for selecting the interventional operation strategy to be used to decrease complications and improve the technical success rate. The endovascular treatment technique for ostial occlusions of the SCA is challenging and warrants further research to improve current operative methods. Further studies involving more patients are required to confirm the advantages and effectiveness of the angiographic morphology typing.

\section{Acknowledgements}

The authors of the present study would like to thank Dr Shuai Shao (Department of Dermatology, Xijing Hospital, Fourth Military Medical University, Xi'an, China) for her comprehensive help, as well as Professor Qing-Wu Yang and Associate Professor Yong Liu (Department of Neurology, Xinqiao Hospital, Third Military Medical University, Chongqing, China) for their case data. This work was supported by a grant from the National Natural Science Foundation of China (grant no. 81270406).

\section{References}

1. Aiello F and Morrissey NJ: Open and endovascular management of subclavian and innominate arterial pathology. Semin Vasc Surg 24: 31-35, 2011.

2. Brott TG, Halperin JL, Abbara S, Bacharach JM, Barr JD, Bush RL, Cates CU, Creager MA, Fowler SB, Friday G, et al: 2011 ASA/ACCF/AHA/AANN/AANS/ACR/ASNR/CNS/SAIP/SCAI/ SIR/SNIS/SVM/SVS guideline on the management of patients with extracranial carotid and vertebral artery disease. A report of the American college of cardiology Foundation/American heart association task force on practice guidelines, and the American stroke association, American association of neuroscience nurses, American association of neurological surgeons, American college of radiology, American society of neuroradiology, congress of neurological surgeons, society of atherosclerosis imaging and prevention, society for cardiovascular angiography and interventions, society of interventional radiology, society of neurointerventional surgery, society for vascular medicine, and society for vascular surgery. Circulation 124: e54-e130, 2011.
3. Modarai B, Ali T, Dourado R, Reidy JF, Taylor PR and Burnand KG: Comparison of extra-anatomic bypass grafting with angioplasty for atherosclerotic disease of the supra-aortic trunks. Br J Surg 91: 1453-1457, 2004.

4. Delaney CP, Couse NF, Mehigan D and Keaveny TV: Investigation and management of subclavian steal syndrome. Br J Surg 81: 1093-1095, 1994.

5. Satti SR, Golwala SN, Vance AZ and Tuerff SN: Subclavian steal: Endovascular treatment of total occlusions of the subclavian artery using a retrograde transradial subintimal approach. Interv Neuroradiol 22: 340-348, 2016.

6. Noguchi T, Miyazaki MD S, Morii I, Daikoku S, Goto Y and Nonogi H: Percutaneous transluminal coronary angioplasty of chronic total occlusions. Determinants of primary success and long-term clinical outcome. Catheter Cardiovasc Interv 49: 258-264, 2000.

7. Palchik E, Bakken AM, Wolford HY, Saad WE and Davies MG: Subclavian artery revascularization: an outcome analysis based on mode of therapy and presenting symptoms. Ann Vasc Surg 22: 70-78, 2008.

8. Seldinger SI: Catheter replacement of the needle in percutaneous arteriography: A new technique. Acta Radiol 39: 368-376, 1953.

9. Bachman DM and Kim RM: Transluminal dilatation for subclavian steal syndrome. Am J Roentgenol 135: 995-996, 1980.

10. Mathias K, Staiger J, Thron A, Spillner G, Heiss HW and Konrad-Graf S: Percutaneous transluminal dilatation of the subclavian artery (author's transl). Dtsch Med Wochenschr 105: 16-18, 1980 (In German).

11. Westerband A, Rodriguez JA, Ramaiah VG and Diethrich EB: Endovascular therapy in prevention and management of coronary-subclavian steal. J Vasc Surg 38: 699-704, 2003.

12. De Vries JP, Jager LC, Van den Berg JC, Overtoom TC, Ackerstaff RG, Van de Pavoordt ED and Moll FL: Durability of percutaneous transluminal angioplasty for obstructive lesions of proximal subclavian artery: Long-term results. J Vasc Surg 41: 19-23, 2005.

13. Wang KQ, Wang ZG, Yang BZ, Yuan C, Zhang WD, Yuan B, Xing T, Song SH, Li T, Liao CJ and Zhang Y: Long-term results of endovascular therapy for proximal subclavian arterial obstructive lesions. Chin Med J (Engl) 123: 45-50, 2010.

14. Paukovits TM, Lukács L, Bérczi V, Hirschberg K, Nemes B and Hüttl K: Percutaneous endovascular treatment of innominate artery lesions: A single-centre experience on 77 lesions. Eur J Vasc Endovasc Surg 40: 35-43, 2010.

15. Higashimori A, Morioka N, Shiotani S, Fujihara M, Fukuda K and Yokoi Y: Long-term results of primary stenting for subclavian artery disease. Catheter Cardiovasc Interv 82: 696-700, 2013.

16. Bates MC, Broce M, Lavigne PS and Stone P: Subclavian artery stenting: Factors influencing long-term outcome. Catheter Cardiovasc Interv 61: 5-11, 2004.

17. Brountzos EN, Malagari K and Kelekis DA: Endovascular treatment of occlusive lesions of the subclavian and innominate arteries. Cardiovasc Intervent Radiol 29: 503-510, 2006.

18. Brountzos EN, Petersen B, Binkert C, Panagiotou I and Kaufman JA: Primary stenting of subclavian and innominate artery occlusive disease: A single center's experience. Cardiovasc Intervent Radiol 27: 616-623, 2004.

19. González A, Gil-Peralta A, González-Marcos JR and Mayol A: Angioplasty and stenting for total symptomatic atherosclerotic occlusion of the subclavian or innominate arteries. Cerebrovasc Dis 13: 107-113, 2002.

20. Henry M, Henry I, Polydorou A, Polydorou A and Hugel M: Percutaneous transluminal angioplasty of the subclavian arteries. Int Angiol 26: 324-340, 2007.

21. Martinez R, Rodriguez-Lopez J, Torruella L, Ray L, Lopez-Galarza L and Diethrich EB: Stenting for occlusion of the subclavian arteries. Technical aspects and follow-up results. Texas Hear Inst J 24: 23-27, 1997.

22. Patel SN, White CJ, Collins TJ, Daniel GA, Jenkins JS Reilly JP, Morris RF and Ramee SR: Catheter-based treatment of the subclavian and innominate arteries. Catheter Cardiovasc Interv 71: 963-968, 2008

23. Woo EY, Fairman RM, Velazquez OC, Golden MA, Karmacharya J and Carpenter JP: Endovascular therapy of symptomatic innominate-subclavian arterial occlusive lesions. Vasc Endovascular Surg 40: 27-33, 2006.

24. Karpenko A, Starodubtsev V, Ignatenko P and Gostev A: Endovascular treatment of the subclavian artery steno-occlusive disease. J Stroke Cerebrovasc Dis 26: 87-93, 2017. 
25. Miyakoshi A, Hatano T, Tsukahara T, Murakami M, Arai D and Yamaguchi S: Percutaneous transluminal angioplasty for atherosclerotic stenosis of the subclavian or innominate artery: Angiographic and clinical outcomes in 36 patients. Neurosurg Rev 35: 121-126, 2012.

26. Aziz F, Gravett MH and Comerota AJ: Endovascular and open surgical treatment of brachiocephalic arteries. Ann Vasc Surg 25: 569-581, 2011.

27. Sixt S, Rastan A, Schwarzwälder U, Bürgelin K, Noory E, Schwarz T, Beschorner U, Frank U, Müller C, Hauk M, et al: Results after balloon angioplasty or stenting of atherosclerotic subclavian artery obstruction. Catheter Cardiovasc Interv 73: 395-403, 2009.

28. AbuRahma AF, Bates MC, Stone PA, Dyer B, Armistead L, Scott Dean L and Scott Lavigne P: Angioplasty and stenting versus carotid-subclavian bypass for the treatment of isolated subclavian artery disease. J Endovasc Ther 14: 698-704, 2007.

29. Przewlocki T, Kablak-Ziembicka A, Pieniazek P, Musialek P, Kadzielski A, Zalewski J, Kozanecki A and Tracz W: Determinants of immediate and long-term results of subclavian and innominate artery angioplasty. Catheter Cardiovasc Interv 67: 519-526, 2006.

30. Henry M, Amor M, Henry I, Ethevenot G, Tzvetanov K and Chati Z: Percutaneous transluminal angioplasty of the subclavian arteries. J Endovasc Surg 6: 33-41, 1999.

31. Sueoka BL: Percutaneous transluminal stent placement to treat subclavian steal syndrome. J Vasc Interv Radiol 7: 351-356, 1996.
32. Criado FJ and Queral LA: The role of angioplasty and stenting in the treatment of occlusive lesions of supra-aortic trunks. J Mal Vasc 21 (Suppl A): S132-S138, 1996.

33. Kumar K, Dorros G, Bates MC, Palmer L, Mathiak L and Dufek C: Primary stent deployment in occlusive subclavian artery disease. Cathet Cardiovasc Diagn 34: 281-285, 1995.

34. Mathias KD, Lüth I and Haarmann P: Percutaneous transluminal angioplasty of proximal subclavian artery occlusions. Cardiovase Intervent Radiol 16: 214-218, 1993.

35. Stone GW, Kandzari DE, Mehran R, Colombo A, Schwartz RS Bailey S, Moussa I, Teirstein PS, Dangas G, Baim DS, et al: Percutaneous recanalization of chronically occluded coronary arteries: A consensus document: Part I. Circulation 112: 2364-2372, 2005.

36. Sumitsuji S, Inoue K, Ochiai M, Tsuchikane E and Ikeno F: Fundamental wire technique and current standard strategy of percutaneous intervention for chronic total occlusion with histopathological insights. JACC Cardiovasc Interv 4: 941-951, 2011.

37. Surmely JF, Katoh O, Tsuchikane E, Nasu K and Suzuki T: Coronary septal collaterals as an access for the retrograde approach in the percutaneous treatment of coronary chronic total occlusions. Catheter Cardiovasc Interv 69: 826-832, 2007.

38. Ozawa N: A new understanding of chronic total occlusion from a novel PCI technique that involves a retrograde approach to the right coronary artery via a septal branch and passing of the guidewire to a guiding catheter on the other side of the lesion. Catheter Cardiovasc Interv 68: 907-913, 2006. 